\title{
An approach to a novel insect growth regulator buprofezin (Applaud ${ }^{\circledR}$ )
}

\author{
H. Kanno \\ Chemical Research Center, Nihon Nohyaku Co., Ltd., Nishiyodogawa, \\ Osaka, Japan
}

\begin{abstract}
A variety of 1,3,5-dithiazines and 1,3,5-thiadiazines were synthesized from N-substituted-N-chloromethylcarbamoyl chlorides and bifunctional nucleophiles, such as ketene dithiolates and thioureas, to investigate their biological activity. In the cyclization reaction of $\mathrm{N}-$ substituted-N-chloromethylcarbamoy1 chlorides with thioureas or thioamides, the chloromethyl group reacted selectively with sulfur of these nucleophiles to give 1,3,5-thiadiazin-4-ones without any isomers. A sterically less bulky substituent of unsymmetrical 1,3-dialky1thiourea was introduced to 3 -position of the cyclized product.

Some perhydro-1,3,5-thiadiazines among the several derivatives were found to show insect growth regulating activity against Nilaparvata lugens. The study on the structure-activity relationships showed that a 2-imino group was essential, and both bulky alkyl groups on 2-imino nitrogen and 3position were also important to show potent activity. 2-tert-Butylimino-3isopropy1-5-pheny1perhydro-1,3,5-thiadiazin-4-one (buprofezin) was found to be the most active and species specific insect growth regulator.
\end{abstract}

\section{INTRODUCTION}

In our laboratory we studied the syntheses of heterocyclic compounds containing sulfur and their biological activity. In the course of the study, the reactivity of some intermediates derived from organo sulfur compounds, such as carbon disulfide and isothiocyanates, was also extensively examined.

One of the effetive methods to create a new bioactive compound is to modify synthetically a known compound that has biological activity. Isoprothiolane $\underline{2}$ developed as a systemic fungicide for rice blast showed growth regulating activity both on some plants and insects (ref. 1-3). The novelty of chemical structure and the variety of biological activity of $\underline{2}$ attracted our attention as a lead compound for a new pesticide chemical.<smiles>CN1C(=O)N(c2ccccc2)CS/C1=N\CO</smiles>

$\underline{1}$ (Buprofezin)

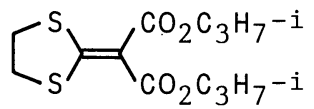

$\underline{2}$ (Isoprothiolane)

At first, we planned to introduce amide moiety, known to be an important partial structure of many bioactive compounds, into the dithiolane ring of 2 . For this purpose, key intermediates $\mathrm{N}$-substituted-N-chloromethylcarbamoy 1 chlorides $\underline{3}$ were prepared. The reaction of $\underline{3}$ with ketene dithiolates $\underline{4}$ proceeded smoothly to give 1,3,5-dithiazin-4-ones $\underline{6}$. We expected to find pesticidal activity in the compounds, but no remarkable activity was found. However, the smooth reaction of the dichlorides $\underline{3}$ with dithiolates $\underline{4}$ encouraged us to turn to the syntheses of new heterocyclic compounds using the compound $\underline{3}$ and several S,N-containing bifunctional nucleophiles such as thioureas, thioamides and dithiocarbamates.

\section{SYNTHESES OF N-SUBSTITUTED-N-CHLOROMETHYLCARBAMOYL CHLORIDES}

A few authors have reported the syntheses of $\mathrm{N}$-chloromethylcarbamoyl chlorides $\underline{3}$ by the addition of phosgene to azomethyne or perhydro-s-triazine (ref. 4-8), or by the chlorination of $\mathrm{N}$-substituted-N-methylcarbamoy1 chlorides (ref. 6, 8). The reaction of trichloromethyl chloroformate with azomethyne or perhydro-s-triazine derivatives also gave $\underline{3}$ (Fig. 1$)$. Although these methods usually gave $\underline{3}$ in good yield, we searched for a new method to avoid using poisonous phosgene. We found chlorination of $\mathrm{N}$-ary $1-\mathrm{N}-m e t h y 1$ formamides gave $\underline{3}$ also in good yield (ref. 9). 


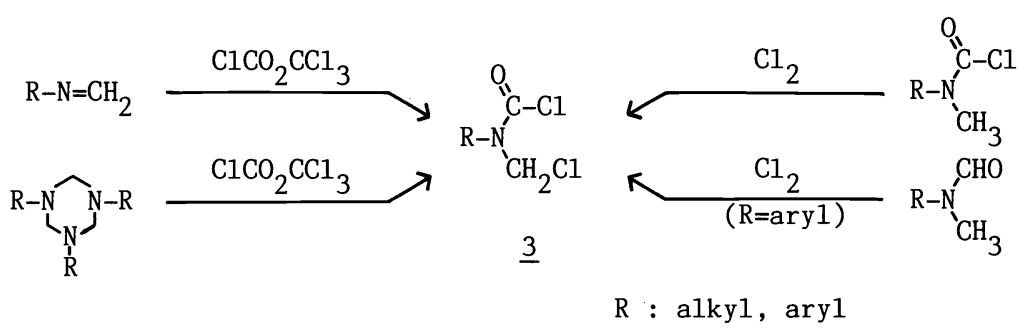

Fig. 1. Syntheses of $\mathrm{N}$-substituted-N-chloromethylcarbamoy1 chlorides

Most of $\underline{3}$ obtained by this method were stable enough to be purified by distillation or recrystallization.

\section{SYNTHESES OF 1,3,5-DITHIAZINES}

Ketene dithiolates $\underline{4}$, which are useful intermediates for the syntheses of heterocycles including dithiolane derivatives 5 ( $r$ f. 1), were prepared from active methylene compounds and carbon disulfide in the presence of 2 moles of base (ref. 1). Dihydro-1,3,5-dithiazin-4-ones 6 were synthesized from the dichlorides 3 and the dithiolates 4 as shown in Fig. 2. A mixture of two isomers was obtained in most cases when the substituent $\bar{X}$ and $Y$ were different (ref. 10).

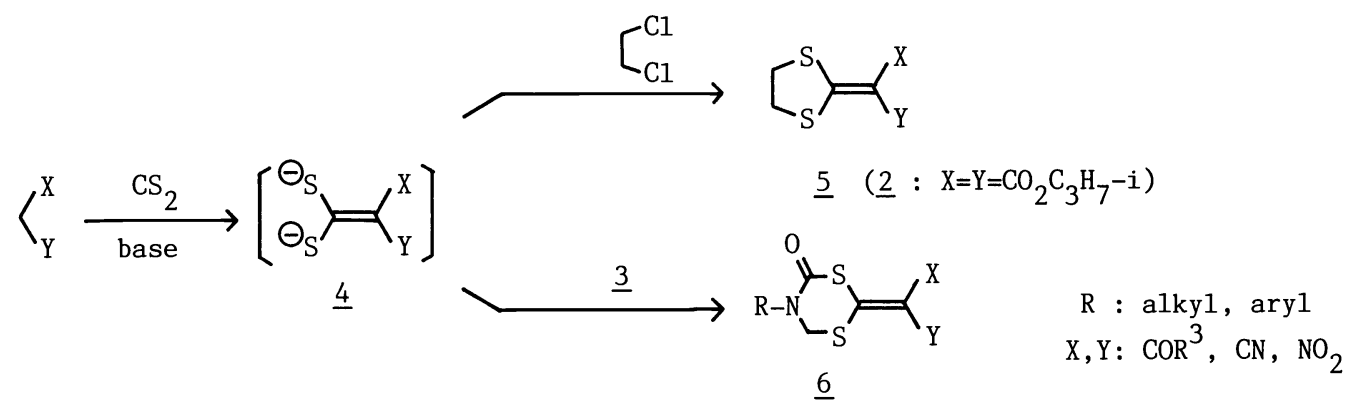

Fig. 2. Syntheses of dithiolane and dithiazine derivatives

The selective reactivity of the chloromethyl group of $\underline{3}$ with some nucleophiles was elucidated by König (ref. 8). We found that both the chloromethyl and carbamoyl groups of 3 reacted with thioalcohols under mild conditions in the presence of base. In fact, the cyclization to the dithiazines 6 proceeded at room temperature probably first at the more reactive chloromrthyl group of $\underline{3}$ with the thiolate group of $\underline{4}$ as suggested by König, and followed by the reaction of the carbamoyl group of $\underline{3}$ with another thiolate group of the same molecule to afford the cyclized product.

\section{SYNTHESES OF 1,3,5-THIADIAZINES}

When the dichlorides 3 were reacted with 1,1-disubstitutedthioureas 7 in the presence of 2 moles of base, dihydro-1,3,5-thiadiazin-4-ones $\underline{9}$ were obtained selectively without isomer $\underline{11}$

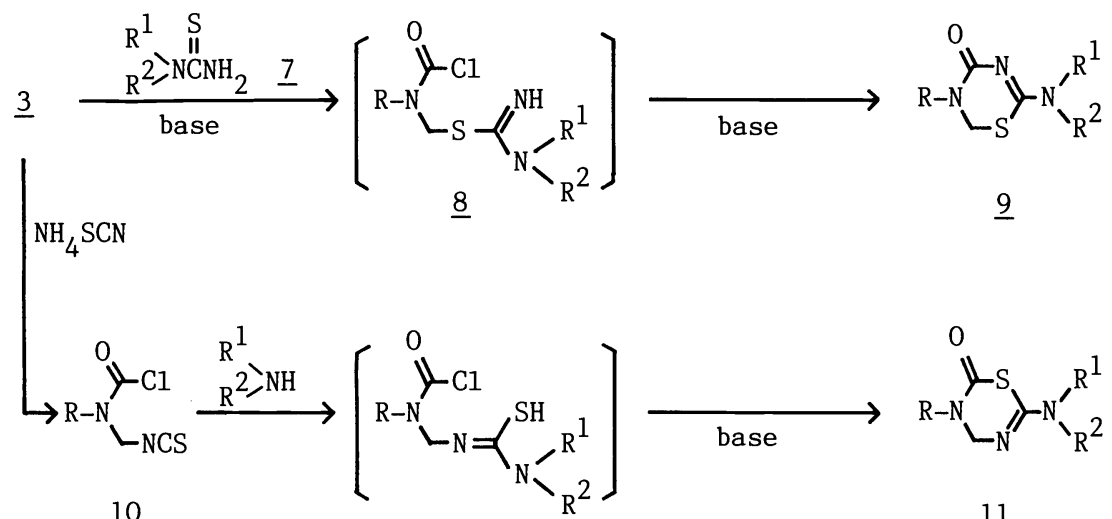

Fig. 3. Syntheses of dihydro-1,3,5-thiadiazines 
(ref. 11) (Fig. 3). In order to determine the structure of $\underline{9}$, the syntheses of the isomeric compounds 11 were carried out via isothiocyanate derivatives $\underline{10}$ according to the reported method (ref. 12).

The preferential formation of the compounds 9 indicated that the cyclization reaction occured in such a manner that the chloromethyl group of $\underline{3}$ was first attacked by the sulfur of thiourea 7 to form the intermediate 8 , then the carbamoy 1 group by the imino nitrogen. This is plausible, considering the difference in reactivity between the chloromethyl group and the carbamoyl group, and the fact that the thiol in thiourea has generally more reactive nucleophilicity than the amino group has against alkyl halides.

Reaction of 1,3-disubstitutedthioureas $\underline{12}$ with $\underline{3}$ afforded perhydro-1,3,5-thiadiazin-4-ones 13, but the possible product thioxo-1,3,5-triazine was not detected (ref. 11, 13, 14). Other new heterocyclic compounds $\underline{14}, \underline{15}$, and $\underline{16}$ from $\underline{13}$ were synthesized as followes (Fig. 4):

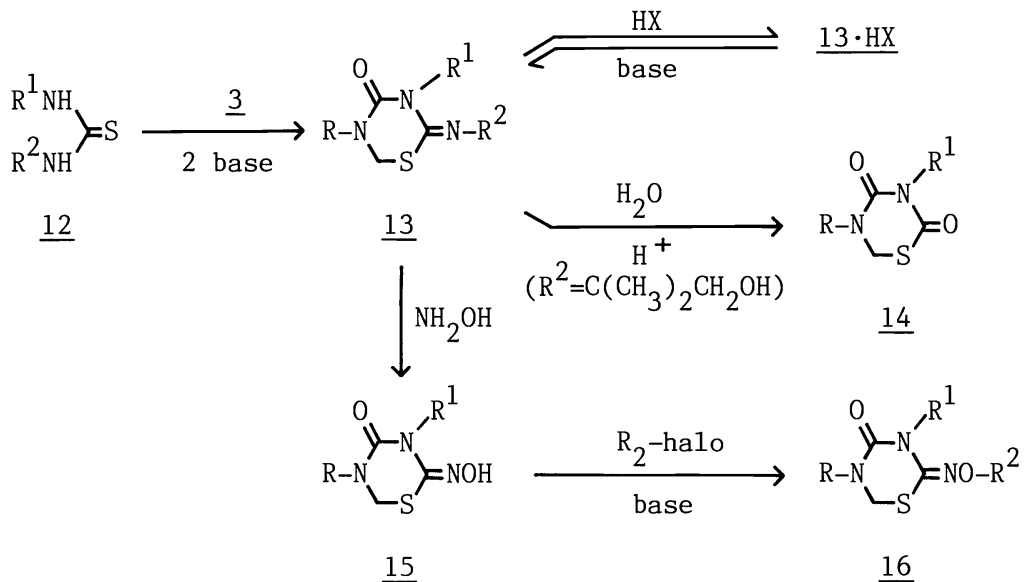

Fig. 4. Syntheses of perhydro-1,3,5-thiadiazine derivatives

2-Iminothiadiazines possessing $\beta$-hydroxyalky1 substituents on the imino nitrogen were easily hydrolyzed in the presence of acid to give thiadiazin-2,4-diones 14, although most alkyl or ary1 derivatives of 13 were stable enough to afford only acid salts $13 \cdot \mathrm{HX}$. The compound 2,4diones 14 were important to determine the position of substituents in 13 when $R^{1}$ and $R^{2}$ were different. Replacement of alkylimino of 13 by hydroxyimino group was carried out by the reaction of hydroxylamine hydrochloride with 13 in the presence of pyridine (ref. 15). 2-Alkoxyimino derivatives $\underline{16}$ were synthesized by alkylation of $\underline{15}$.

In the cyclization reaction for obtaining 2-imino-1,3,5-thiadiazin-4-ones 13, hydrogen chloride salts of 13 were easily obtained even in the presence of one mole of base. Accordingly, the supposed isothioureas (a) and (b) were not isolated. The formation of two isomers 13 and 17 was expected when $R^{1}$ and $R^{2}$ of 12 were different via the tautomeric intermediates (A) and (B) (Fig. 5).

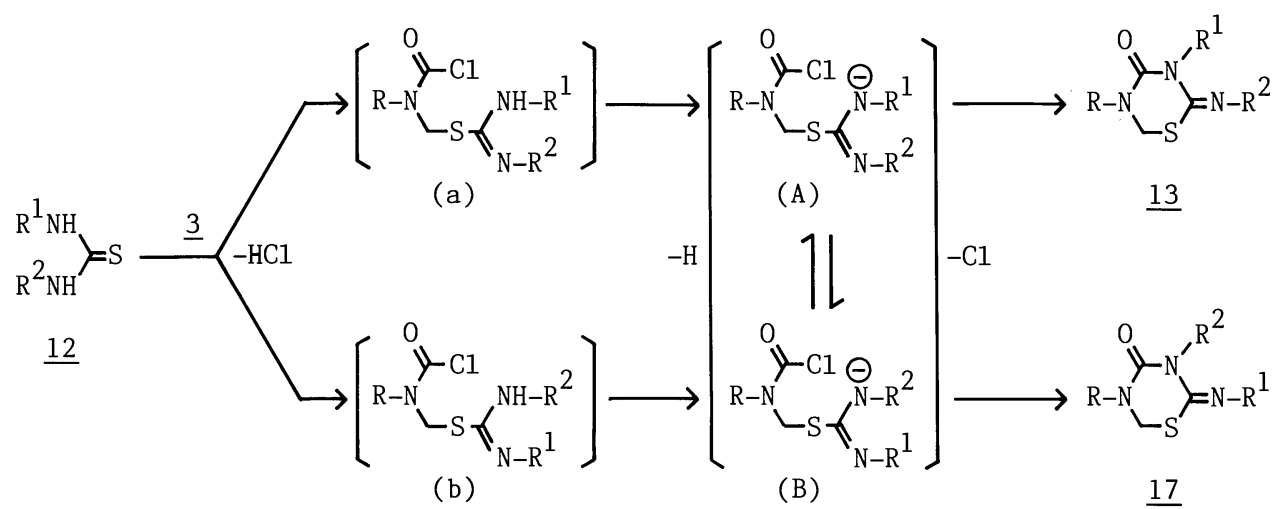

Fig. 5. Cyclization reaction to 2-iminoperhydro-1,3,5-thiadiazin-4-ones

The ratio of formation of $\underline{13}$ and $\underline{17}$ is of some interest (Table 1). Two isomers were formed when the differences in steric size of $R^{1}$ and $R^{2}$ were small. However, it is noted that tertbutyl group was always located on imino nitrogen ( $e, f)$. It is likely that the more basic and less hindered nitrogen is attacked by carbamoyl chloride. 
TABLE 1. Production ratio of two isomers of

\begin{tabular}{|c|c|c|c|c|c|}
\hline Compound No. & $\mathrm{R}$ & $\mathrm{R}^{1}$ & $\mathrm{R}^{2}$ & $\operatorname{Ratio}^{\mathrm{a}}(\%)$ & Yield (\%) \\
\hline $\begin{array}{l}\frac{13}{17}-\mathrm{a} \\
\underline{1}-\mathrm{a}\end{array}$ & (0) & 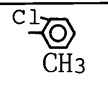 & ${ }^{\mathrm{Cl}} \frac{\mathrm{CH}_{3}}{-0)}$ & $\begin{array}{l}67 \\
33\end{array}$ & 82 \\
\hline $\begin{array}{l}\frac{13}{17}-\mathrm{b} \\
\underline{-b}\end{array}$ & (0) & $\begin{array}{l}\mathrm{n}-\mathrm{C}_{3} \mathrm{H}_{7} \\
\mathrm{i}-\mathrm{C}_{4} \mathrm{H}_{9}\end{array}$ & $\begin{array}{l}\mathrm{i}-\mathrm{C}_{4} \mathrm{H} 9 \\
\mathrm{n}-\mathrm{C}_{3} \mathrm{H} 7\end{array}$ & $\begin{array}{l}63 \\
37\end{array}$ & 84 \\
\hline $\begin{array}{l}\frac{13}{17}-\mathrm{c} \\
\underline{17}-\mathrm{c}\end{array}$ & (0) & $\begin{array}{l}\mathrm{i}-\mathrm{C}_{3} \mathrm{H}_{7} \\
\mathrm{~s}-\mathrm{C}_{4} \mathrm{H}_{9}\end{array}$ & $\begin{array}{l}\mathrm{s}-\mathrm{C}_{4} \mathrm{H}_{9} \\
\mathrm{i}-\mathrm{C}_{3} \mathrm{H}_{7}\end{array}$ & $\begin{array}{l}60 \\
40\end{array}$ & 91 \\
\hline $\begin{array}{l}\frac{13}{13}-\mathrm{d} \\
\frac{13}{13}-\mathrm{f} \\
\underline{13}-\mathrm{g}\end{array}$ & $\begin{array}{c}\text { (a) } \\
\text { i- } 3 \mathrm{C}^{-} \mathrm{H}_{7} \\
\text { (0) }\end{array}$ & $\begin{array}{c}\mathrm{n}-\mathrm{C}_{3} \mathrm{H}_{7} \\
\mathrm{i}-\mathrm{C}_{3} \mathrm{H}_{7} \\
-\mathrm{O} \\
\mathrm{i}-\mathrm{C}_{3} \mathrm{H}_{7}\end{array}$ & $\begin{array}{r}\mathrm{s}-\mathrm{C}_{4} \mathrm{H} 9 \\
\mathrm{t}-\mathrm{C}_{4} \mathrm{H} 9 \\
\mathrm{t}-\mathrm{C}_{4} \mathrm{H} 9 \\
\mathrm{CO}_{2} \mathrm{C}_{2} \mathrm{H}_{5}\end{array}$ & $\begin{array}{l}100 \\
100 \\
100 \\
100\end{array}$ & $\begin{array}{l}89 \\
92 \\
76 \\
43\end{array}$ \\
\hline
\end{tabular}

${ }^{\text {a Determined by }}{ }^{1}$ Hnmr analysis.

Other thiadiazines synthesized are shown in Fig. 6. 2-Thioxo-1,3,5-thiadiazines 19 were prepared from sodium salt of dithiocarbamate $\underline{18}$ and $\underline{3}$ in the presence of one mole of sodium hydroxide (ref. 16). Compounds 19 were also synthesized by Belei (ref. 17) using triethylammonium salt of $\underline{18}$, an additional mole of triethylamine and $\underline{3}$.

Other S,N-containing nucleophilic reagents, thioamides $\underline{20}$ and $\underline{22}$, were reacted respectively with $\underline{3}$ in the presence of 2 moles of base to give dihydro $\underline{21}$ and perhydrothiadiazines $\underline{23}$ (ref. 16).

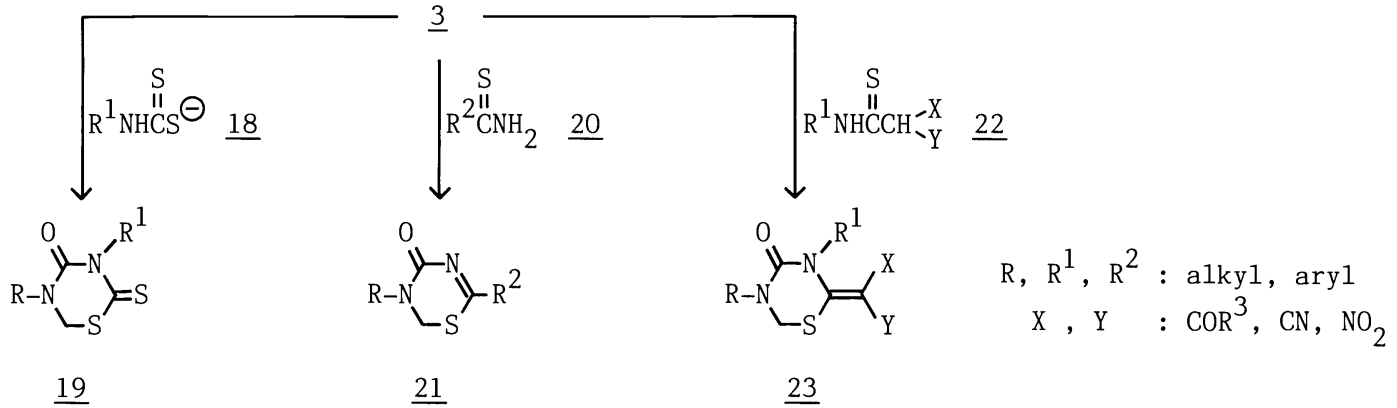

Fig. 6. Syntheses of dihydro- and perhydro-1,3,5-thiadiazines

\section{STRUCTURE-ACTIVITY RELATIONSHIPS}

Among the compounds described above, some perhydrothiadiazines showed insect growth regulating activity on the brown planthopper (Nilaparvata lugens) (ref. 11, 14, 18, 19), which is regarded as one of the most serious insect pests in rice fields. Activity of these compounds against the third instar nymphs of $\underline{N}$. lugens assayed on rice plant is summarized in Table 2 . It is suggested that the imino group on 2-position of perhydrothiadiazine is essential to be effective. The data in Table 2 also indicate that the activity of 5-ary1 derivatives are superior to those of alkyl derivatives, although the cyclohexyl derivative (13-j) is fairly effective.

Further investigation clarified the relationship between the substituents on two nitrogens at 2-, 3-positions of 2-imino-5-pheny1perhydro-1,3,5-thiadiazin-4-ones and the activity. Insect growth regulating activity of these compounds is given in Table 3 . The compounds that have two branched alkyls demonstrate effective pesticidal activity.

Quantitative structure-activity relationships were studied in 17 compounds with 2-alky1 and 3alkylimino groups employing the 4th instar nymphs of N. 1ugens (ref. 20). Regression analysis gave the following equation:

$$
\begin{aligned}
& \mathrm{pLD}_{50}=-0.569 \pi^{1}-0.624 \pi^{2}+3.560 \mathrm{~B}_{1}{ }^{1}+0.596 \mathrm{~B}_{1}{ }^{2}-4.43 \\
& \mathrm{n}=17 \quad \mathrm{r}=0.951 \quad \mathrm{~s}=0.170 \quad \mathrm{~F}=28.7 \\
& \text { pLD50 : a logarithm of median dose in } \mu \mathrm{mol} / \mathrm{g} \text { insect by topical application } \\
& \text { on the } 4 \text { th instar nymphs of } \underline{N} \text {. lugens } \\
& \pi^{1}, \pi^{2} \text { : hydrophobic parameter at } \mathrm{R}^{1} \text { and } \mathrm{R}^{2} \\
& \mathrm{~B}_{1}{ }^{1}, \mathrm{~B}_{1}{ }^{2} \text { : sterimo1 parameter at } \mathrm{R}^{1} \text { and } \mathrm{R}^{2}
\end{aligned}
$$


TABLE 2. Activity of perhydro-1,3,5-thiadiazines on the third instar nymphs of $\mathrm{N}$. lugens

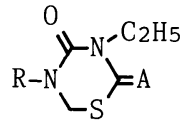

\begin{tabular}{|c|c|c|c|c|}
\hline \multirow[b]{2}{*}{ Compound No. } & \multirow[b]{2}{*}{$\mathrm{R}$} & \multirow[b]{2}{*}{ A } & \multicolumn{2}{|c|}{ Mortality $^{\mathrm{a}}(\%)$} \\
\hline & & & $400 \mathrm{ppm}$ & $100 \mathrm{ppm}$ \\
\hline 19-a & (0) & $\mathrm{S}$ & 0 & 0 \\
\hline 14-a & (0) & 0 & 0 & 0 \\
\hline$\overline{15}-\mathrm{a}$ & (0) & $\mathrm{NOH}$ & 0 & 0 \\
\hline$\overline{23}-a$ & (0) & $\mathrm{C}\left(\mathrm{CO}_{2} \mathrm{C}_{3} \mathrm{H}_{7}-\mathrm{i}\right)_{2}$ & 0 & 0 \\
\hline$\overline{13}-\mathrm{h}$ & (a) & $\mathrm{NC}_{3} \mathrm{H}_{7}-\mathrm{i}$ & 95 & 45 \\
\hline $13-i$ & (Q) & $\mathrm{NC}_{3} \mathrm{H}_{7}-\mathrm{i}$ & 95 & 25 \\
\hline$\underline{13}-j$ & $\frac{U N}{(H)}$ & $\mathrm{NC}_{3} \mathrm{H}_{7}-\mathrm{i}$ & 95 & 10 \\
\hline$\overline{13}-\mathrm{k}$ & $t-\mathrm{C}_{4} \mathrm{H}_{9}$ & $\mathrm{NC}_{3} \mathrm{H}_{7}-\mathrm{i}$ & 0 & 0 \\
\hline $13-1$ & $\mathrm{CH}_{3}$ & $\mathrm{NC}_{3} \mathrm{H}_{7}-\mathrm{i}$ & 0 & 0 \\
\hline
\end{tabular}

$a_{\text {Five days after treatment. }}$

TABLE 3. Activity of perhydro-1,3,5-thiadiazines on the third instar nymphs of $\underline{N}$. lugens

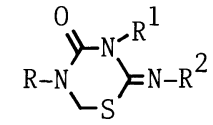

\begin{tabular}{|c|c|c|c|c|}
\hline \multirow[b]{2}{*}{ Compound No. } & \multirow{2}{*}{$\mathrm{R}^{1}$} & \multirow{2}{*}{$R^{2}$} & \multicolumn{2}{|c|}{ Mortality $^{\mathrm{a}}(\%)$} \\
\hline & & & $10 \mathrm{ppm}$ & $2.5 \mathrm{ppm}$ \\
\hline $13-m$ & $\mathrm{H}$ & $\mathrm{H}$ & 0 & 0 \\
\hline $\mathrm{n}$ & $\mathrm{C}_{2} \mathrm{H}_{5}$ & $\mathrm{C}_{2} \mathrm{H}_{5}$ & 0 & 0 \\
\hline $\mathrm{h}$ & $\mathrm{C}_{2} \mathrm{H}_{5}$ & $\mathrm{i}-\mathrm{C}_{3} \mathrm{H}_{7}$ & 20 & 0 \\
\hline o & i- $\mathrm{C}_{4} \mathrm{H}_{9}$ & $\mathrm{~s}-\mathrm{C}_{4} \mathrm{H}_{9}$ & 15 & 0 \\
\hline $\mathrm{p}$ & $\mathrm{i}-\mathrm{C}_{3} \mathrm{H}_{7}$ & $\mathrm{i}-\mathrm{C}_{3} \mathrm{H}_{7}$ & 75 & 40 \\
\hline e (1 $)$ & $\mathrm{i}-\mathrm{C}_{3} \mathrm{H}_{7}$ & $\mathrm{t}-\mathrm{C}_{4} \mathrm{H} 9$ & 100 & 95 \\
\hline$q$ & (a) & $t-\mathrm{C}_{4} \mathrm{H} 9$ & 0 & 0 \\
\hline $\mathrm{r}$ & $\mathrm{i}-\mathrm{C}_{3} \mathrm{H}_{7}$ & $\mathrm{co}\langle 0\rangle$ & 0 & 0 \\
\hline s & $\mathrm{N}\left(\mathrm{CH}_{3}\right)_{2}$ & $\mathrm{t}-\mathrm{C}_{4} \mathrm{H} 9$ & 0 & 0 \\
\hline
\end{tabular}

${ }^{\mathrm{a}}$ Five days after treatment.

TABLE 4. Activity of perhydro-1,3,5-thiadiazines on the third instar nymphs of $\mathrm{N}$. lugens

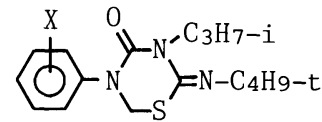

\begin{tabular}{cccc}
\hline & & \multicolumn{2}{c}{ Mortality $^{\mathrm{a}}(\%)$} \\
\cline { 3 - 4 } Compound No. & $\mathrm{X}$ & $10 \mathrm{ppm}$ & $2.5 \mathrm{ppm}$ \\
\hline \multirow{2}{*}{$13-\mathrm{e}(1)$} & $\mathrm{H}$ & 100 & 95 \\
$\mathrm{t}$ & $4-\mathrm{CH}_{3}$ & 100 & 100 \\
$\mathrm{u}$ & $3-\mathrm{CH}_{3}$ & 95 & 45 \\
$\mathrm{v}$ & $2,4-\left(\mathrm{CH}_{3}\right)_{2}$ & 95 & 32 \\
$\mathrm{w}$ & $3-\mathrm{Cl}_{3}$ & 85 & 35 \\
$\mathrm{x}$ & $4-\mathrm{CH} 3$ & 40 & 0 \\
$\mathrm{y}$ & $4-\mathrm{Cl}$ & 0 & 0 \\
\hline
\end{tabular}

$\mathrm{a}_{\text {Five days after treatment. }}$

The steric and hydrophobic properties of molecules, especially the sterimol length $B_{1}$ at $R^{1}$ is significant. The compound 13-e gave the maximum activity by pLD50; 2.14 as calculated and 2.11 as observed.

The introduction of some substituents on 5-phenyl ring generally reduced the activity. As shown in Table 4, non-substituted(13-e) and 4-methyl(13-t) derivatives exhibited potent activity.

From the structure-activity correlation studies, the compounds $13-e$ and $13-t$ were selected for the development of a new pesticide. After extensive biological (ref. 18, 21-24), toxicological (ref. 19) and chemical studies (ref. 16), the compound 13-e was successfully developed as a new insect growth regulator, and named buprofezin. 


\section{BIOLOGICAL CHARACTERISTICS OF BUPROFEZIN}

Buprofezin is highly effective against several species of insect pests, such as planthoppers, leafhoppers, whiteflies and scales, and is quite harmless for beneficial insects, natural enemies, fishes and mammals (ref. 19, 21-25). The activities against nymphs of planthoppers and leafhoppers are 10 to 140 times more potent than conventional carbamates or organophosphrous insecticides (ref. 19, 21).

Most of nymphs of $\mathrm{N}$. lugens treated with buprofezin died during the ecdysis, 3 to 5 days after exposure (ref. 16, 18, 19, 21, 22, 25). Effects on adults were also characteristic : (1) shortened longevity ; (2) suppressive oviposition ; (3) deposition of unhatchable eggs (ref. $16,19,21,24)$. Thus, buprofezin has the growth regulating activity and exhibits excellent pest control effects for a long period in practical application (ref. 16, 18, 19, 21, 25).

\section{CONCLUSION}

$\mathrm{N}$-Substituted-N-chloromethylcarbamoyl chlorides were found to be a useful reagent for the syntheses of new heterocyclic compounds, and many 1,3,5-thiadiazines were synthesized and evaluated for their biological activity. Among them, 2-tert-butylimino-3-isopropy1-5-phenylperhydro-1,3,5-thiadiazin-4-one (buprofezin) was found to be very active against some insect pests, and therefore commercialized as a new insect growth regulator.

\section{REFERENCES}

1. K. Taninaka, J. Pesticide Sci. 3, 203 (1978).

2. M. Fukada and T. Miyake, Appl. Entomol. Zool. 22, 191 (1977).

3. T. Sugimoto, F. Araki and K. Taninaka, J. Pesticide Sci. 2 505 (1977).

4. J.P. Chupp, J. Org. Chem. 33, 2357 (1968).

5. H. Kiefer, Synthesis 1972,39 .

6. H. Ulrich, R. Richter, P.J. Whitman and A.A.R. Sayigh, J. Org. Chem. 39, 2897 (1974).

7. K.H. König and H. Pommer, Ger. Pat. 1269611 (1968).

8. K.H. König, H. Pommer, H. Kiefer and A. Müller, Pesticide Chemistry, Proc. 2nd Int. IUPAC Congr., 1, p.433, Gorden \& Breach Science Publishers, New York, London Paris (1972).

9. K. Yabutani, H. Kodama and M. Yamamoto, Jpn. Tokkyo Koho JP 6129942 (1986).

10. K. Ikeda, S. Kubota, U. Miyagi and F. Araki, Jpn. Kokai Tokkyo Koho JP 604177 (1985).

11. K. Ikeda, H. Kanno and M. Yasui, Pesticide Chemistry, Proc. 5th Int. IUPAC Congr., 1 , p.141, Pergamon Press, Oxford, New York, Tronto, Sydney, Paris, Frankfurt (1982).

12. J.P. Chupp, J. Heterocyclic Chem. 8 , 677 (1981).

13. K. Ikeda, H. Kanno, M. Yasui and S. Maekawa, The 6th Annu. Meet. of Pesticide Sci. Soc. of Jpn. Abstr., 108 (1981).

14. H. Kanno, K. Ikeda, M. Yasui and S. Maekawa, The 6th Annu. Meet. of Pesticide Sci. Soc. of Jpn. Abstr., 109 (1981).

15. D.F. Bushy and F.C. Hoover, J. Org. Chem. 45, 4198 (1980).

16. K. Ikeda, M. Yasui, H. Kanno and S. Maekawa, J. Pesticide Sci. 11, 287 (1986).

17. I. Belai, P. Sohar and K. Maekawa, J. Heterocyclic Chem. 18,283 (1981).

18. S. Maekawa and K. Ikeda, The 25th Annu. Meet. of Jpn. Soc. of App1. Entomol. and Zool. Abstr. 56 (1981).

19. H. Kanno, K. Ikeda, T. Asai and S. Maekawa, Proc. 1981 Br. Crop Prot. Conf. Pests Dis. p.59, BCPC Publication, London (1981).

20. K. Ikeda, Biorational Approach for Pesticide Design, p.193, Soft Science Co., Tokyo (1986).

21. O. Kajihara, T. Asai, K. Ikeda and S.S. Lim, Proc. Int. Conf. Plant Prot. Tropics p.1 (1982).

22. T. Asai, M. Fukada, S. Maekawa, K. Ikeda and H. Kanno, Appl. Entomo1. Zoo1. 18, 550 (1983).

23. M. Yasui, M. Fukada and S. Maekawa, App1. Entomol. Zool. 20, 340 (1985).

24. T. Asai, 0. Kajihara, M. Fukada and S. Maekawa, Appl. Entomol. Zool. 20, 111 (1985).

25. M. Shibuya, Jpn. Pestic. Inf. 44, 17 (1984). 